\title{
CONDUCTIVITY MEASUREMENT FOR CONTROL OF A BIOGAS PLANT
}

\author{
Richard Klein ${ }^{1}$, Vlastimil Slaný ${ }^{1}$, Eva Krčálová ${ }^{1}$ \\ ${ }^{1}$ Department of Agricultural, Food and Environmental Technology, Faculty of AgriSciences, Mendel university in \\ Brno, Zemedelska 1, 61300 Brno, Czech Republic
}

To cite this article: KLEIN RICHARD, SLANÝ VLASTIMIL, KRČÁLOVÁ EVA. 2018. Conductivity Measurement for Control of a Biogas Plant. Acta Universitatis Agriculturae et Silviculturae Mendelianae Brunensis, 66(5): 1151-1156.

To link to this article: https://doi.org/10.11118/actaun201866051151

\begin{abstract}
Nowadays in these modern times, when the majority of technologies are dependent on electrical energy, it is necessary to build new sources of energy ecologically and still improve their efficiency. One of the branches, which can contribute to ecology, is biogas plants. When biogas production methods are properly applied in them, these biogas plants have two advantages. One of them is the disposal of biowaste, the other is the production of green electricity in cogeneration units. In this article, steps which will enable better control of biogas transformations are listed. Therefore, they will contribute to the eco biogas production. The innovative approach involves adding new control variable. This variable can be shown in advance of the reaction, as evidenced by the charts. Results for evaluation were measured in the bioreactor during 20 experiments. Most (14) experiments were identical with residues from wine. The residue measurement was performed on three experiments in the remaining biomaterials. The course of production of methane always copied progress conductivity. This fact is evident from the graphs on Figs. 2-4. The methods used for data processing were: removal creeping values, statistic methods (median, average) and interpolation. It can be concluded from the results that the conductivity of digestate predicts specific production of biogas.
\end{abstract}

Keywords: conductivity, biogas, automatization, pipe senzor

\section{INTRODUCTION}

The dependence of developed countries on energy is very high. Therefore, it is necessary to use all available sources of precious energy. However, the problem of the use of energy sources is the impact on the environment. Biogas plants with cogeneration units can solve two problems.

The first problem of the developed and agriculturally developed countries is the excess of biowaste, which needs to be dumped or somehow disposed of. However, it might be demanding in terms of space needed for storage, processing or its transport. Hygienic norms are very often the problem with the treatment of biowaste.
A weak point of biogas plants is their control, which is precisely set to one batch type. In such a case, it is necessary to provide the biogas plant with the same biological material. A serious problem to the future is the continual expansion of the agricultural biogas plants which need just the corn silage for their activities. Corn cultivation has high demands on nutrients in soil, moreover, corn fields are prone to run-off soil.

This problem could be solved by adaptive control of the biotransformation process. If the composition of the batch reasonably quickly changes, then the whole system will adjust at the slight reduction of the biogas production to the new batch type. For such a procedure, not only 
theoretical mathematical model but also a real measurement is needed. The ideal case would be to find a physical quantity which will predict the biogas production or the quality of biogas.

Currently measured quantities in the National Laboratory of biogas transformations are the temperature of water between the inner and outer coats, digestate, $\mathrm{pH}$, volume and the quality of biogas. Due to the large amount of digestate buffer, the $\mathrm{pH}$ change will take effect when approaching the boundary values. It is very similar to the buffer capacity of proteins in the mouth; it maintains a relatively constant pH. (Slezakova et al., 2016). For the biogas transformation, the compounds in the digestate are similar to proteins in the mouth.

Other measured quantities are temperatures which manage the activity of the biological process. These are only a tool, not quantities that determine how to manage the whole process. Temperatures for the control of anaerobic biogas transformations have been known for quite a long time. The first biogas plants were founded in the 60 s of the $20^{\text {th }}$ century. In their book called Ecological Agriculture (Petr and Dlouhý, 1992), they described control as an ecological solution.

We were considering other options of simple measurement solutions, which could be conclusive. A book called Biophysics by J. Rozina et al. (2013) brought us to a possible solution. In a cell, there are a lot of sugars and metabolic products similar to the biological process of biotransformation. This publication has given us the idea to connect conductivity with the production of biogas. Therefore, we were looking for a quantity which is needed in private sector. Operators of the biogas stations are obviously most interested in the amount of produced biogas but for more accurate analysis, calculated specific methane production, which is the main component of biogas, is more preferable.

\section{MATERIALS AND METHODS}

The first problem to solve is rather engineering because custom-made production of the probe is very expensive. For this reason, we had to use a sensor, which is serially manufactured. However, this sensor has never been designed for liquid immersion. A standard attachment of conductivity sensors is to the wall of a thick-walled pipe and the fluid flows around. For this reason, the sensor has only one external thread, which serves for the attachment to the pipe. Therefore, we had to design a product which enables to immerse the sensor to the digestate.

\section{Attachment of the conductivity probe}

The conductivity probe and its attachment had to fulfil the following so that the whole would provide accurate information and would not influence further measurements and ongoing experiments. Otherwise, adjustments would have to be done.

The first problem was the material which has to withstand compounds which are produced during anaerobic biological processes. A more accurate description of the emerging compounds is given in the Biogas manual, (Moreno, 2011; Alburquerque, 2012; Noskovič 2013) and Argentina and its immense potential to set up biogas plants, (Gubinelli, 2015). For this purpose, water or sewer pipes are suitable.

Polypropylene pipes, which can be sealed by welding, are ideal because they are firm and at the same time chemically resistant. Other possible materials are polyethylene and polytetrafluoroethylene. For example for the flare nut, we have used polyethylene components. At the end of the product, a sensor itself with a basket with cover is installed against larger organic residues, which may short-circuit electrodes of the conductivity probe described in Fig 1.

The sketch of pipe prolongation is used for immersion sensor below the surface of the digestate. It was necessary to produce such a prolongation because it does not produce a sensor with a sufficiently long body.

This product, thanks to its detachable central part, enables by a simple exchange of the upper part a various sensor immersion depth in the digestate. Such an easily adjustable product enables measurements which are needed within

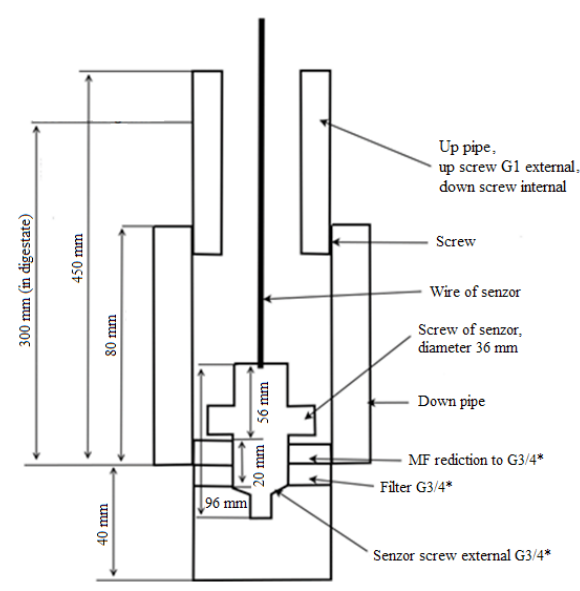

1: Sketch of new sensor pipe prolongation 
automated precise control. Because the biological process takes place mainly on the surface and since the biological material mostly floats on the surface, it is not suitable to place the sensor there. If the sensor is placed close to the bottom, measurements can be affected by sediments and dirt located at the bottom. Measurements currently carried out serve only to find the relations between the conductivity and specific methane production.

\section{The system of measurement Methods of measurement}

One of the important parts of the system for scientific purposes is to obtain data from sensors that must meet the requirements of scientific data. The main emphasis is given to the accuracy of the interpreted data, temperature compensation, limiting the impact of properties of the components used with main and parasitic characteristics and the measurement with the smallest deviation possible, avoiding interference and noise in the measured signals by shielding or appropriate modulation magnitudes less prone to interference, eg. current loops, digital signals.

Similar measurement from different perspectives made at the University of KwaZulu-Nata, however, not looking for a relationship between conductivity and the production of methane. But methods of measurement are similar. In this article, the range of conductivity in the bioreactor is $5-21 \mathrm{mS}$ (Moreno, 2011). Large fermenters each have measuring of all the physical and chemical quantities separately, even though the unit for measuring the quality of biogas is only one. Therefore, the entire measurement must be recorded in the database. Measurement times are adjustable; therefore, an experiment will be the first complete data block that will be worked with later on. Other values which will have to be coordinated to the specific time and date will have to be calculated using mathematical conversions. This mainly concerns the measurements which cannot be accelerated by software and which are dependent on the construction of the meter. It is about Hall probe with gas which is able to always indicate the whole rotation of analogue digit (this digit represents llitre). If we want to know the volume of produced biogas between two measurements of volume, there is nothing except spacing the curve by the last points and assume that the search point is on the straight line. In such cases, it is recommended to interpret the date to the volume of produced biogas retrospectively, not to predict the future values.

At large fermenters, the following quantities are monitored:

- the temperature of biomass

- the temperature between the inner and outer coats

- biogas temperature

- revolutions and the mixing time

- the consumption of electrical energy (calculated)

- the level of digestate

- gasometer state (the volume of produced biogas)

- $\mathrm{pH}$ if the probe is active
- conductivity if the probe is present

- chemical composition of biogas $\left(\mathrm{CH}_{4}, \mathrm{CO}_{2}, \mathrm{H}_{2} \mathrm{~S}, \mathrm{H}_{2}\right)$ Measurement frequency is one of the most difficult settings of the entire system. The general rule, of course, is that the more measurements there are for us, the more accurate the result is but it also depends on other parameters which need to be taken into account. One such variable is the speed of response of the entire biological process on the change, which does not happen in seconds, but in the order of hours if exceeding the inhibiting factors of biological processes within several times is not taken into account. Another important condition which must be reflected in the samples is the number of fermenters. Also from time to time, the biogas from the testing fermenters needs to be measured or drained away.

For calculating the maximum speed of the measurement of chemical quantities from large fermenters, the following parameters are important:

- The amount of produced gas: the amount differs depending on its course, the production is between 1,5-1501/day

- The time after mixing: mixing has a great influence on the release of produced biogas from solid particles contained in the digestate. Therefore, chemical composition before and after mixing may vary.

- The number of fermenters: if we count the total length of time needed for one fermenter, then the next measurement will be possible after measurement of all other fermenters

- The length of one measurement: the length in which sensors are able to accurately determine the chemical element contained in the biogas is given in the information from the manufacturer

- The length of reinitialization: the length needed for cleaning the sensors from the previous sample is given in the information from the manufacturer

- The length of the sensor warming: is the time delay before the sensor is ready for an accurate measurement, it is also given in the information from the manufacturer

- The amount of gas needed: is the volume required to perform the chemical analysis; each sensor has a specific minimal volume of gas which has to pass through it so that the measurement is accurate; it is given by the sensor manufacturer

- The distance: the length of pipes between the chemical analyser of the biogas and the reactor. It is necessary to fill the volume of the pipes by a new sample in order to ensure a new, unchanged sample for the measurement.

All these conditions affect when it is possible to perform another measurement. The first formula (eq. 1) is needed to calculate the length of production (eq. 2,3) of needed biogas of the fermenter. At large fermenters, the production is sufficient for the whole period except a short period at the end of the measuring cycle. 


$$
t_{v m 1} \geq\left(t_{p}+t_{r}\right) p+t_{s}
$$

- $\mathrm{t}_{\mathrm{vm} 1}$ time of the first measurement

- $\mathbf{t}_{\mathbf{p}}$ time of the biogas flow

- $\mathrm{t}_{\mathrm{r}}$ time of the sensor reinitialization

- $\mathbf{p}$ the number of fermenters

- $\mathbf{t}_{\mathrm{s}}$ time of the start of sensors

$$
t_{v m 1} \geq\left(t_{p}+t_{r}\right)(p+i)
$$

- $\mathbf{i}$ the number of measurements

- $\mathbf{t}_{\mathrm{vmi}}$ the time of a certain number of the measurement

- $t_{\mathrm{p}}$ time of the biogas flow

- $\mathbf{t}_{\mathrm{r}}$ time of the sensor reinitialization
- $\mathbf{p}$ the number of fermenters

$p_{p} \geq p_{m} t_{m}+p_{t r} l$

- $\mathbf{p}_{\mathbf{p}}$ amount of gas needed to perform an analysis

- $\mathbf{p}_{\mathbf{m}}$ minimum gas flow through the sensor

- $\mathbf{t}_{\mathrm{m}}$ time needed for the measurement

- $\mathbf{p}_{\text {tr }}$ volume per lm pipe

- I the length of pipe

Further calculations for the measurement results origin from processing errors, quantization and qualitative data processing. We have calculated the specific production according to standard formulas.

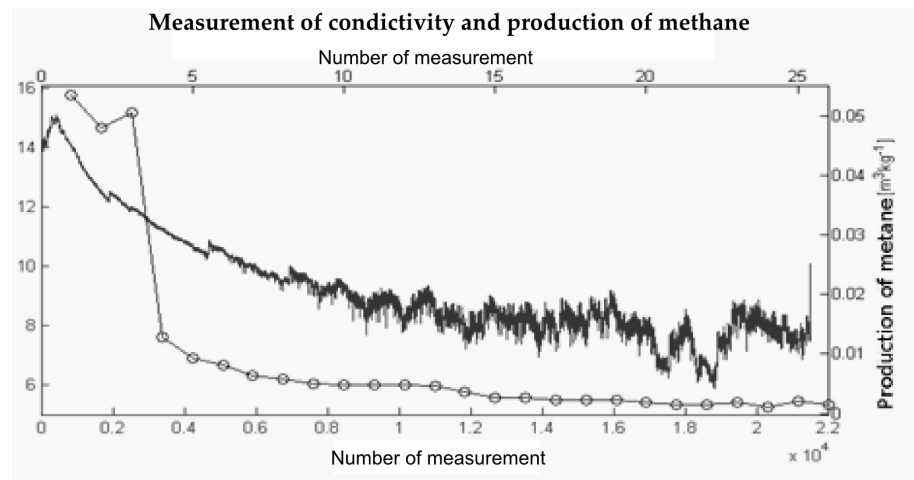

2: Fig. 2 Measuring methane and conductivity 1

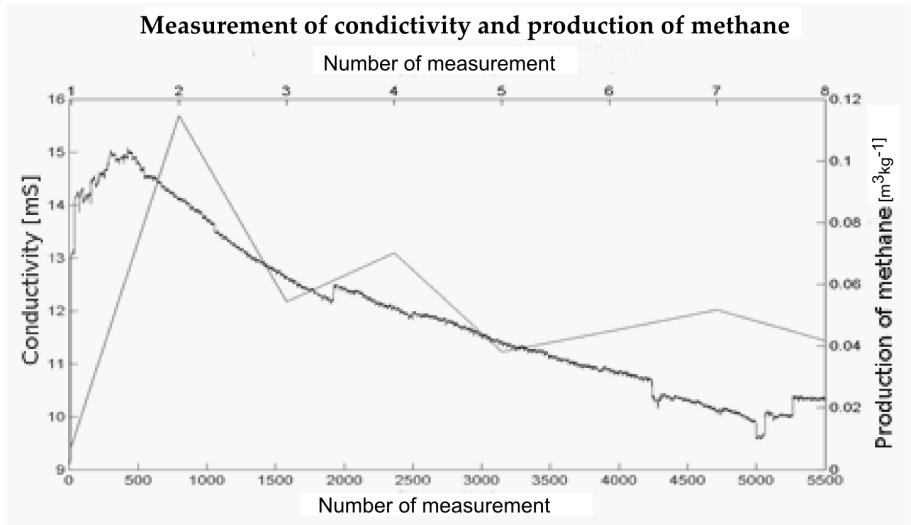

3: Fig. 3 Measuring methane and conductivity 2

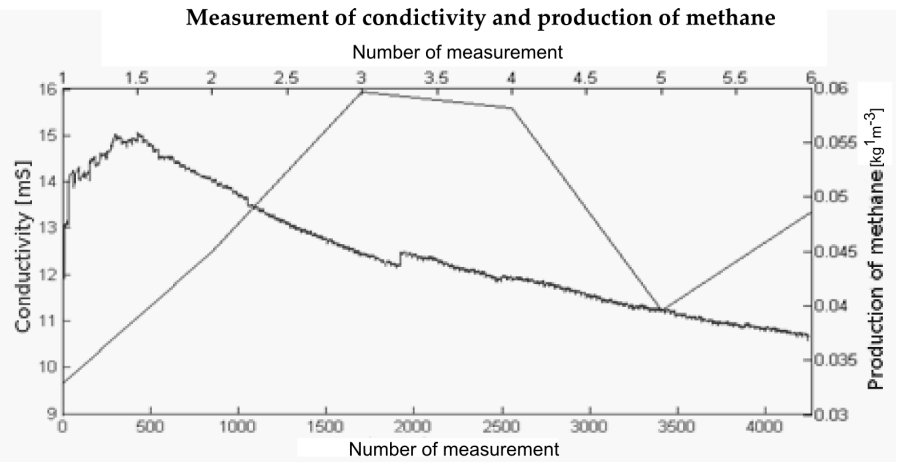

4: Fig. 4 Measuring methane and conductivity 3 


\section{RESULTS AND DISCUSSION}

\section{The results of the measurement}

The measurement, which took half a year, measured data which needed to be processed because one measurement was conducted once a day and the next one was automatic after half a minute. Because of the data imbalance and a resulting considerable deviation, 5 minutes before every single manual measurement, we always took the value from the sensor and assigned it to that value. Afterwards, we recalculated the volume to the specific methane production. The results are shown in the following graphs.

The previous graphs show that the peak conductance leads maximum methane production for half a day to one day. This time is very important if anything is wrong with the production. In this saved time the operation can change the bioreactor run and save the production.

\section{New options of control}

This dependence, which can be seen in the graphs, enables to respond to the change in the system in advance. This knowledge allows developing adaptive programs which adjust the parameters of the biological process so that the system is not overloaded or so that it is able to switch between different types of batch as smoothly as possible.

The addition of new sensors allows tracking a larger number of parameters and thus makes the results more accurate or provides links of individual variables among themselves. Some types of sensors, such as measurement of surface, enable more accurate dosing of the individual components of the whole digestate and therefore, the results of individual measurements will be more accurate. Although it may not be a revolutionary improvement in terms of industrial processing, from the scientific point of view, such improvements can bring new insights into biogas.

\section{DISCUSSION}

The problem in defining the results was in the measurement methodology. The most common method of measurement is discontinuous measurement of samples outside the fermenter. Such as in the case of an article from Kana, 2013. The other measurements we find are semi-automatic when the measurements were repeated but outside the fermenter, as stated in an article by Alburquerque, 2012. All these measurements are influenced by the presence of oxygen when handling the sample. Oxygen is toxic to anaerobic organisms and reacts with compounds in the digestate. However, the resulting curve is the same in its course, as we measured the conductivity. In the articles found by us, no continuous method of conductivity measurement and comparison with biogas quality was dealt with.

\section{CONCLUSION}

Conductivity was a new measured quantity, which, as we have assumed, has the same course as the specific methane production in biogas. As we have shown in the comparative graphs of the measurements which have been supported by the theoretical part, it is clear that decomposition of longer chains of nutrients (sugars, proteins, fat) will be reflected in the conductivity. This conductivity clearly indicates the course and production of methane approximately 1-2 days in advance. It depends on the dynamics of the system; the more it is dynamic, the shorter the period in advance is. Due to the length of one experiment and the fact of having only one sensor, additional measurements, especially with more sensors at once, are important for accurate results. I reckon this objective is fulfilled but further scientific work in this research is needed for accurate results applicable in practice.

\section{Acknowledgements}

The research was financially supported by the AF-IGA IP 2016/44-Proposal for monitoring process data in extreme environments and subsequent automated data processing. (In Czech: Návrh procesu monitoringu dat v exrémních prostř̌edích a následné automatizované zpracování naměřených dat.)

\section{REFERENCES}

KANA, E. B. G., SCHMIDT, S. R. H. and KENFACK, R. H. A. 2013. A web-enabled software for real-time biogas fermentation monitoring - Assessment of dark fermentations for correlations between medium conductivity and biohydrogen evolution. International Journal of Hydrogen Energy, 38(25): 10235-10244.

GUBINELLI, G. 2015. Argentina and its immense potential to set up biogas plants [in Spanish: Argentina y su inmenso potencial para montar plantas de biogasg]. Energía Estratégica. [Online]. Available: http://www. energiaestrategica.com/argentina-y-su-inmenso-potencial-para-montar-plantas-de-biogas/ [Accessed: 2016, November 25].

ALbURQUerque, J. A., DE LA FUENTE, C., FERRER-COSTA, A., CARRASCO, L. CEGARRA, J., ABAD, J. M. and BERNAL, M. P. 2012. Assessment of the fertiliser potential of digestates from farm and agroindustrial residues. Biomass and Bioenergy, 40: 181-189. 
MORENO VARNERO, T. M. 2011. Biogas Manual [in Spanish: Manual de biogas]. Santiago de Chile: Remoción de Barreras para la Electrificación Rural con EnergíasRenovables.

NOSKOVIČ, J., BABOŠOVÁ, M., PORHAJAŠOVÁ, J., TÁRNÍK, A. and VARGA, V. Time and Place Changes in pH And Conductivity in the Water of Čaradice Stream [in Slovak: Časové a Priestorové Zmeny pH a Vodivosti vo Vode Čaradického Potoka]. Acta Horticulturae et Regiotectuare, 16(1): 24-28.

PETR, J. and DLOUHÝ, D. 1992. Ecological agriculture [in Czech: Ekologické zemédèlství]. Zemědělské nakladatelství Brázda.

ROZINA, J. VRÁNOVÁ, J., KOLÁŘOVÁ, H. and STANEK, J. 2013. Biophysics: For medical and biomedical fields [in Czech: Biofyzika: pro zdravotnické a biomedicinské obory]. Praha: Grada Publishing a. s.

SLEZÁKOVÄ, L. et al. 2016. Dentistry For Nursing School and College [in Czech: Stomatologie I pro SZŠa VOŠ] Praha: Grada Publishing a.s. 